\title{
Characterize Clustering of Non-Residential Alternating Current Level 2 Electric Vehicle Supply Equipment
}

Idaho National Laboratory

June 2015

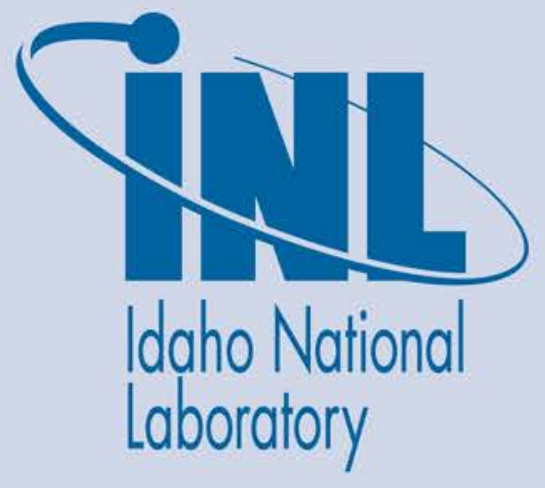

The INL is a U.S. Department of Energy National Laboratory operated by Battelle Energy Alliance 


\section{Characterize Clustering of Non-Residential Alternating Current Level 2 Electric Vehicle Supply Equipment}

Idaho National Laboratory

June 2015

Idaho National Laboratory

Idaho Falls, Idaho 83415

http://www.inl.gov

Prepared for the

U.S. Department of Energy

Assistant Secretary for __, OR Office of

Under DOE Idaho Operations Office

Contract DE-AC07-05ID14517 


\section{Characterize Clustering of Non-Residential Alternating Current Level 2 Electric Vehicle Supply Equipment}

June 2015

\section{Key Conclusions}

- Clustering for non-residential electric vehicle supply equipment (EVSE) may involve neighboring businesses installing EVSE, multiple EVSE installed at a single site, or both.

- "Clustering" of non-residential EVSE at neighboring businesses does not have the same electrical grid impact as residential clustering because the electric utility is typically involved early in the installation process at non-residential sites.

- Because the local electric utility is involved with changes to the business' electrical system when installing the EVSE, no occurrences of transformer malfunctions are known to have occurred during The EV Project.

- When a business adds EVSE, it may require upgraded service to the business, resulting in a requirement to upgrade upstream electrical equipment. This typically results in the electric utility requiring a contribution to construction costs for this upgrade.

\section{Introduction}

EVSE deployed by The EV Project included both residential and non-residential units. Approximately 4,000 non-residential alternating current (AC) Level 2 EVSE were installed in workplace environments, fleet applications, and publicly accessible locations near retail centers, parking lots, and similar locations. The Blink AC Level 2 EVSE is capable of charging at up to $7.2 \mathrm{~kW}$ power, although most vehicles in The EV Project charged at about $3.7 \mathrm{~kW}$. The charge rate and energy consumed to recharge a battery are determined by the plug-in electric vehicles (PEVs) onboard battery management system. Impact on the local electrical grid becomes greater when several EVSE are charging PEVs on a site at the same time or when several commercial EVSE sites are geographically close and charging simultaneously. This may place stress on the local power transformer providing energy to these sites.
What insight can The EV Project data provide in characterizing the effect of several geographically close non-residential EVSE?

\section{Why is This Topic Important?}

A frequently asked question related to PEVs is "What is the impact of PEV charging on the electrical grid?" This question can be directed at the big picture of total utility system load or at the impact to local business. The paper titled, Characterize the Demand and Energy Characteristics of Non-residential Alternating Current Level 2 Electric Vehicle Supply Equipment, ${ }^{1}$ identified the individual characteristics of these non-residential EVSE. The effects of EVSE power requirements adding to business requirements were addressed in What is the Impact of Utility Demand Charges on the Alternating Current Level 2 Host? $^{2}$ The focus of this paper is on "clustering" of Level 2 EVSE in a small geographic area that encompasses several charging site hosts. The effects of clustering on the residential power transformer were investigated in Reference 3.

\section{Data Analyzed}

During installation of non-residential EVSE, several EVSE were frequently deployed at the same site in order to better serve the needs of a growing number of PEV drivers. In fact, the average number of AC Level 2 EVSE per site was 2.58 and varied by market from 1.79 to 3.45 per site. Some sites had 10 or more EVSE installed. The locations of these installations are analyzed herein.

\section{Background}

Typical electrical distribution starts with power generation and stepped up voltage for transmission through high voltage lines to a local substation. At the local substation, it is stepped down to lower voltage levels for distribution to businesses and residential areas. One type of distribution system design is the radial design shown in Figure 1.

The primary feeders of the substation supply power to subfeeders that split and step down the voltage at their associated transformers for further distribution. At the local business level, the input voltage is finally stepped down to the needs of the business through a service transformer (Figure 2).

Typically, the local electric utility is involved with any changes to the electrical systems of its commercial customers. Any additional power requirements (such as addition of AC Level 2 EVSE) will typically involve the electric utility to determine the impacts of the increased power needs. Frequently, the addition of new EVSE will 
require either new electrical service for the EVSE or upgraded electrical service to the business that supplies the EVSE.

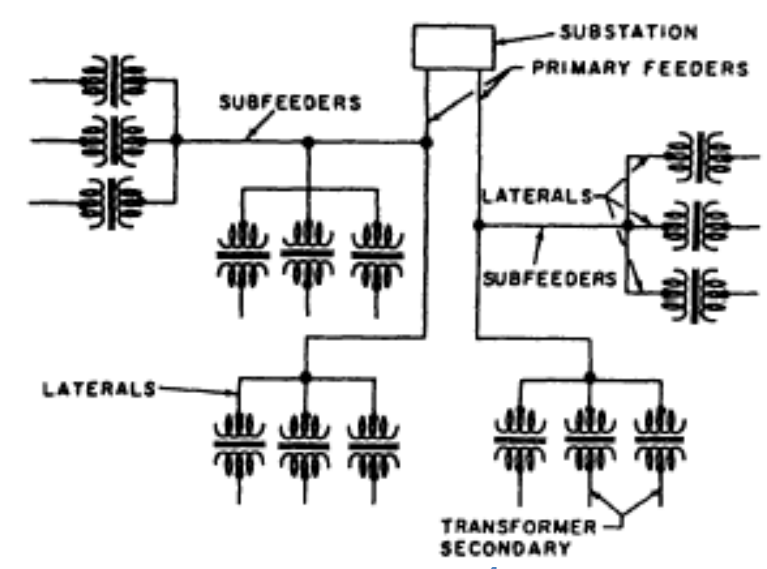

Figure 1. Radial distribution system. ${ }^{4}$
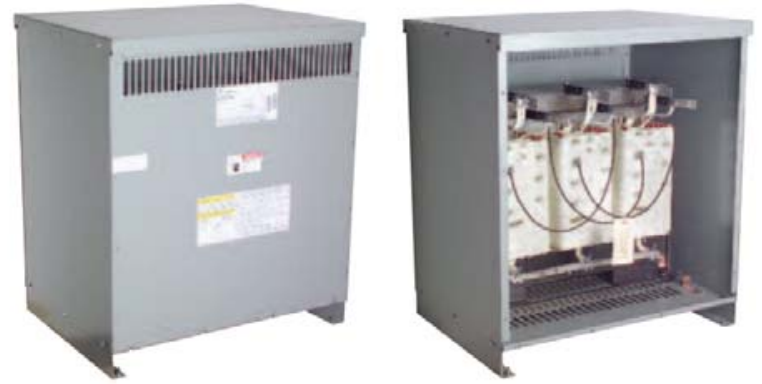

Figure 2. Industrial facility service transformer. ${ }^{5}$

\section{What is Meant by Clustering?}

"Clustering" discussions surrounding PEVs typically involve residential applications. Auto companies know that one factor in vehicle sales is the visibility of a new car in a neighbor's driveway. As a result, neighbors often purchase similar vehicles. When several PEVs reside in the same neighborhood and the residences are powered from the same electrical transformer, "clustering" occurs. This can be a cause for concern to the local electrical utility because of the increase in power being supplied by the transformer. While a transformer can typically accept the power demand increase from one or two PEVs, multiple PEVs charging simultaneously may stress the transformer, resulting in a service outage or the need to upgrade that transformer. Damage caused by overloading the transformer may occur in the short term for significant overloads or in the longer term by depriving the transformer of its normal cool-down period, which usually occurs in the overnight hours. Depending on local permitting requirements, the electric utility may not be aware of when a residential EVSE is installed. Thus, failure of the transformer may be the first indication of any trouble. Reference 3 explores this residential situation in detail.

In the commercial setting, "clustering" would refer to adjoining businesses that might install EVSE or multiple EVSE installed on one site. While each business is typically supplied by its own transformer and the discussion above points out that electric utilities are involved with the addition of new loads (such as EVSE), the utility would also have knowledge of upstream transformer design and capabilities. Thus, if an impact to upstream equipment is expected to occur, the electric utility would include that modification as part of an electrical service upgrade. However, replacing transformers and other electrical distribution equipment is typically an added expense to the business owner desiring to add EVSE.

Electric utilities are subject to regulatory commission or municipal rules. In general, these rules dictate that any service upgrade or extension required by a specific commercial customer on that customer's property is the financial responsibility of the customer. The customer may also be responsible for utility costs off the customer's premises. "All additional Utility electrical facilities attributable to and reasonably related to the development necessary to complete the extension shall be installed by the Utility at the Applicant's expense." If the customer's requested service upgrade affects the upstream distribution system and these upgrades benefit other customers, some costs may be at least partially compensated through funds authorized by the commission rules to be collected from all commercial rate payers.

Although public utilities in California were previously prohibited from owning EVSE, recent rulemaking by the Public Utilities Commission of California may extend the ratepayers financial support of EVSE installed and owned by public utilities in certain cases: "... should utilities present evidence in an appropriate proceeding of underserved markets or market failure in areas where utility involvement is prohibited, we will revisit this prohibition. Should the Commission revisit this issue, we will revisit the concerns outlined above, among others, including the potential cost-subsidization implications of any utility proposal to own public EVSE."7

The electric utility is directly involved in the design and engineering of any upgrades required for EVSE installation; therefore, the system would not likely suffer overloads or unexpected failures. The major impact of clustering for non-residential customers would be financial. These costs may be prohibitive for some commercial customers. 


\section{Non-Residential Clustering of Electric Vehicle Supply Equipment in The EV Project}

Installation locations of non-residential AC Level 2 EVSE placed by The EV Project were investigated. Figures 3 through 7 provide typical examples of these installations. The size of the indicator reflects the number of EVSE installed at that location.

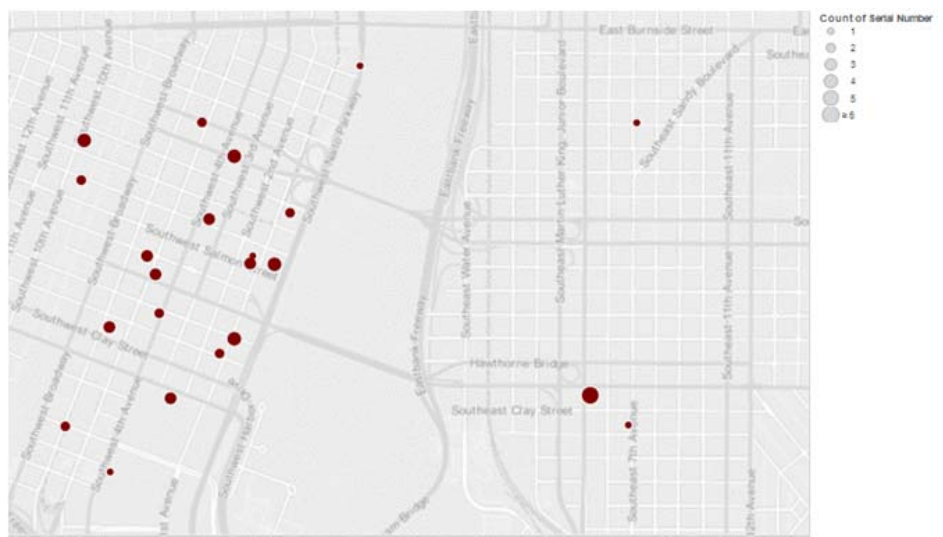

Figure 3. Non-residential AC Level 2 EVSE in Portland, Oregon.

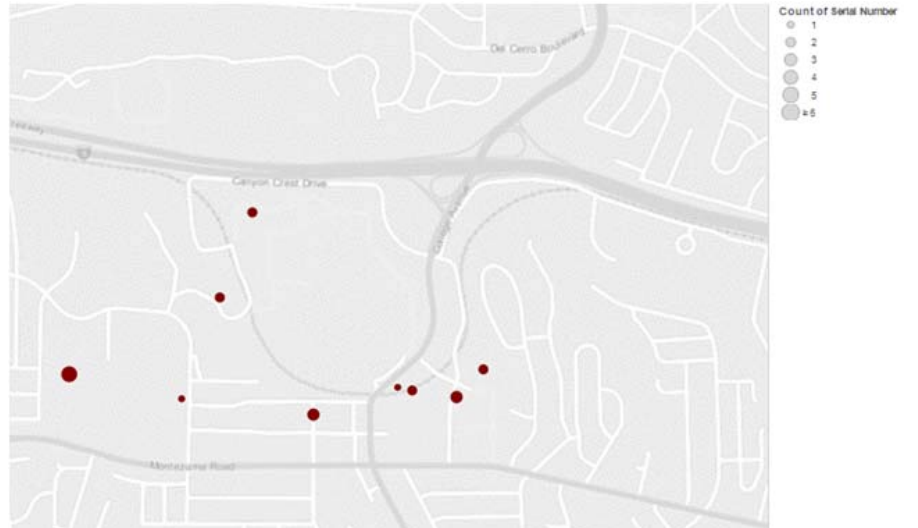

Figure 1. Non-residential AC Level 2 EVSE in San Diego, California.

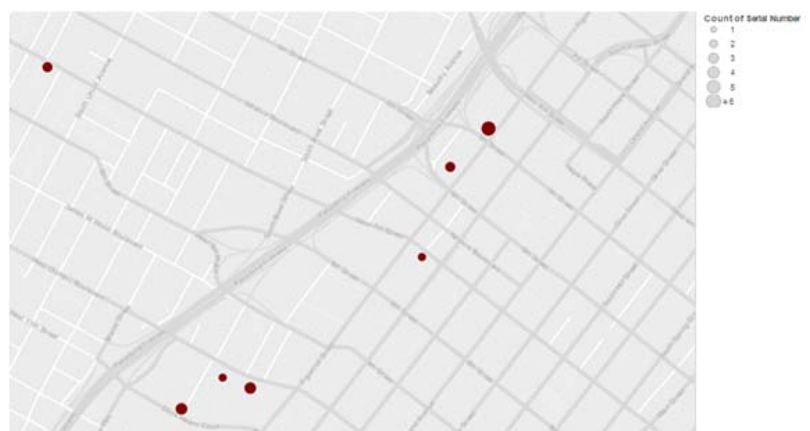

Figure 2. Non-residential AC Level 2 EVSE in Los Angeles, California.

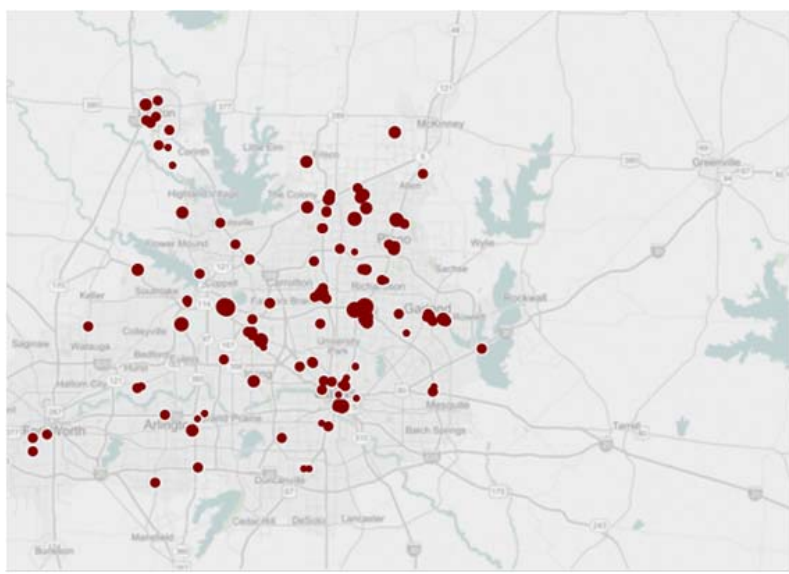

Figure 3. Non-residential AC Level 2 EVSE in Dallas, Texas.

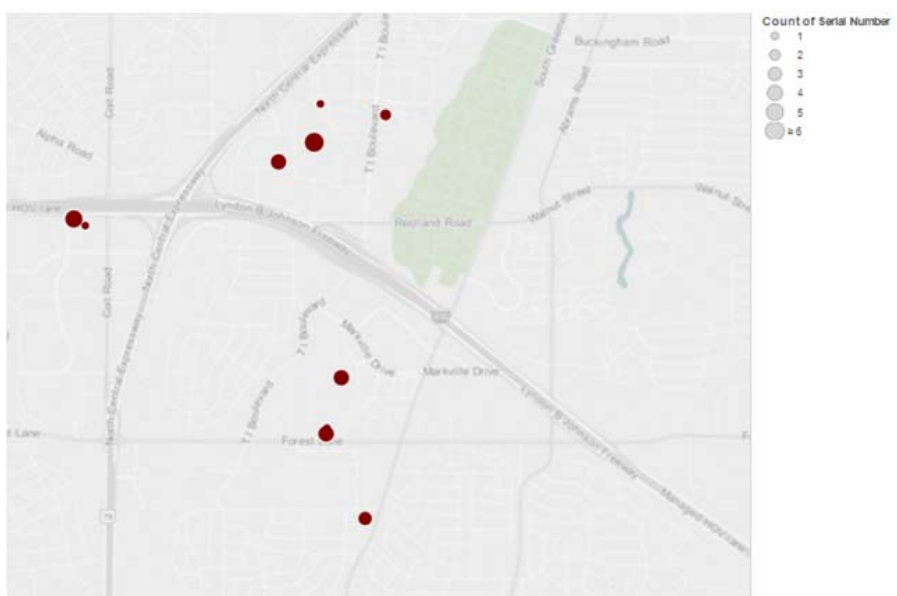

Figure 4. Non-residential AC Level 2 EVSE in central Dallas, Texas.

Significant local EVSE infrastructure exists in each of these cities. However, when isolating specific geographic areas from each city in the EV Project, the dispersion of stations becomes evident. As a result, no clustering effects for non-residential EVSE were noted during The EV Project.

Installation of non-residential EVSE by The EV Project was essentially completed by September 2013. However, installation of non-residential EVSE has continued since that time. Figure 8 shows the locations of AC Level 2 EVSE at the time of this writing in the Portland geographic area (see Figure 3). Several non-Blink EVSE are included.

\section{Conclusions}

Clustering of EVSE during the timeframe of The EV Project was not significant. However, as seen in Figures 3 through 8, concentrations were beginning to occur. Expansion of infrastructure with the adoption of PEVs will increase the potential for these occurrences. 
In addition, clusters that occur from multiple EVSE on the same site add to the potential impact. However, because the electrical supplies to these EVSE have typically been engineered in conjunction with the local electrical utility, clustering issues with the electric grid were not experienced during the term of The EV Project; this would be expected to be common in the future.

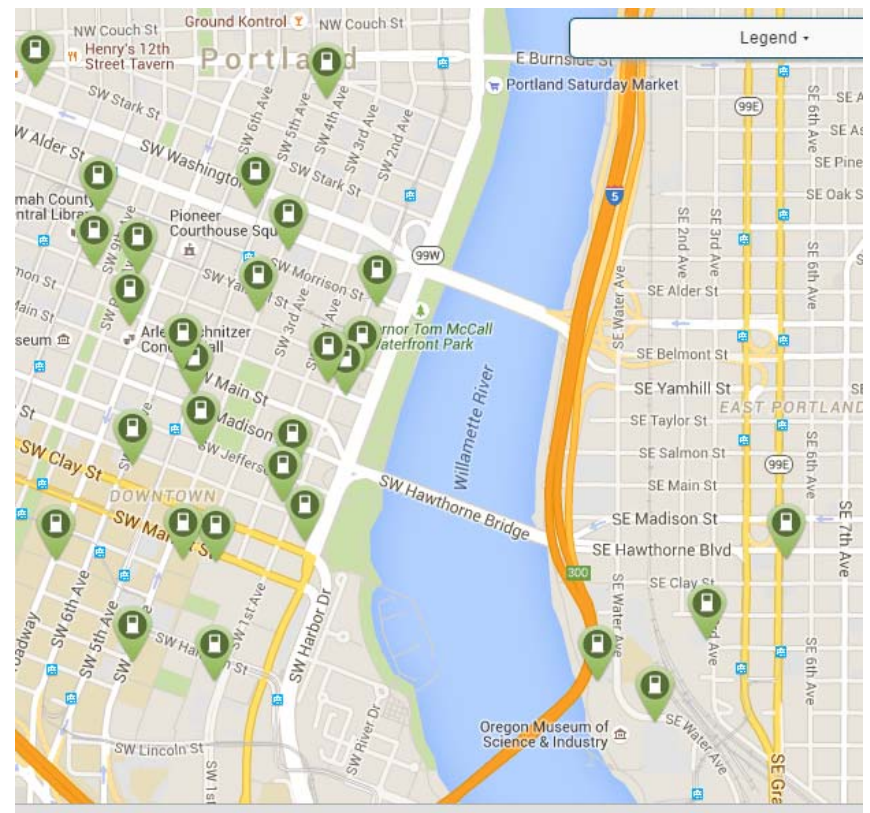

Figure 5. Public AC Level 2 EVSE installations in Portland, Oregon. ${ }^{8}$

The major impact for "clustering" of non-residential EVSE could be increased electrical demand to the charging site host caused by operation of these EVSE (addressed in Reference 2) and increased installation costs for hosts when adding the upstream electrical equipment upgrades.

Finally, "clustering" as a potential issue is generally confined to residential areas due to smaller transformers and a lack of awareness by utilities of the addition of EVSE to the residential customer's service.

\section{About The EV Project}

The EV Project was the largest PEV infrastructure demonstration project in the world, equally funded by the U.S. Department of Energy (DOE) through the American Recovery and Reinvestment Act and private sector partners. The EV Project deployed over 12,000 AC Level 2 charging stations for residential and commercial use and over 100 dual-port direct current fast chargers in 17 U.S. regions. Approximately 8,300 Nissan LEAFs ${ }^{\mathrm{TM}}$, Chevrolet Volts, and Smart ForTwo Electric Drive vehicles were enrolled in the project.
Project participants gave written consent for EV Project researchers to collect and analyze data from their vehicles and/or charging units. Data collected from the vehicles and charging infrastructure represented almost 125 million miles of driving and 4 million charging events. The data collection phase of The EV Project ran from January 1, 2011, through December 31, 2013. Idaho National Laboratory (INL) is responsible for analyzing the data and publishing summary reports, technical papers, and lessons learned on vehicle and charging unit use.

\section{Company Profile}

INL is one of DOE's 10 multi-program national laboratories. The laboratory performs work in each of DOE's strategic goal areas: energy, national security, science, and the environment. INL is the nation's leading center for nuclear energy research and development. Day-to-day management and operation of the laboratory is the responsibility of Battelle Energy Alliance.

For more information, visit avt.inl.gov/evproject.shtml and avt.inl.gov/chargepoint.shtml.

\section{References}

1. "Characterize the Demand and Energy Characteristics of Non-residential AC L2 EVSE," avt.inl.gov/evproject.shtml

2. "What is the Impact of Utility Demand Charges on an AC Level 2 EVSE host?," avt.inl.gov/evproject.shtml

3. "What Residential Clustering Effects have been Experienced in the San Diego Region?," http://avt.inl.gov/pdf/EVProj/ClusteringInSanDiego.p df

4. http://www.tpub.com/inteng/2b.htm

5. http://apps.geindustrial.com/publibrary/checkout/DE A-492B?TNR=Brochures|DEA-492B|generic

6. http://www.riversideca.gov/utilities/pdf/2011/ELEC\% 20RULE\%2010\%20clean\%20cc\%2012-142010\%20-\%20effective\%202-12-11.pdf'

7. http://docs.cpuc.ca.gov/PublishedDocs/Published/G 000/M143/K682/143682372.PDF

8. www.plughare.com, accessed June 7, 2015 